\title{
Review Article \\ Central Modulation of Neuroinflammation by Neuropeptides and Energy-Sensing Hormones during Obesity
}

\author{
Roger Maldonado-Ruiz, ${ }^{1,2}$ Lizeth Fuentes-Mera, ${ }^{3}$ and Alberto Camacho ${ }^{2,3}$ \\ ${ }^{1}$ Laboratory of Virology and Immunology, Faculty of Life Sciences, Autonomous University of Nuevo Leon, \\ San Nicolás de los Garza, NL, Mexico \\ ${ }^{2}$ Neurometabolism Unit, Center for Research and Development in Health Sciences, Autonomous University of Nuevo Leon, \\ San Nicolás de los Garza, NL, Mexico \\ ${ }^{3}$ Biochemistry Department, Faculty of Medicine, Autonomous University of Nuevo Leon, San Nicolás de los Garza, NL, Mexico \\ Correspondence should be addressed to Alberto Camacho; acm590@hotmail.com
}

Received 26 May 2017; Revised 19 July 2017; Accepted 24 July 2017; Published 23 August 2017

Academic Editor: Anna Di Vito

Copyright (C) 2017 Roger Maldonado-Ruiz et al. This is an open access article distributed under the Creative Commons Attribution License, which permits unrestricted use, distribution, and reproduction in any medium, provided the original work is properly cited.

Central nervous system (CNS) senses energy homeostasis by integrating both peripheral and autonomic signals and responding to them by neurotransmitters and neuropeptides release. Although it is previously considered an immunologically privileged organ, we now know that this is not so. Cells belonging to the immune system, such as B and T lymphocytes, can be recruited into the CNS to face damage or infection, in addition to possessing resident immunological cells, called microglia. In this way, positive energy balance during obesity promotes an inflammatory state in the CNS. Saturated fatty acids from the diet have been pointed out as powerful candidates to trigger immune response in peripheral system and in the CNS. However, how central immunity communicates to peripheral immune response remains to be clarified. Recently there has been a great interest in the neuropeptides, POMC derived peptides, ghrelin, and leptin, due to their capacity to suppress or induce inflammatory responses in the brain, respectively. These may be potential candidates to treat different pathologies associated with autoimmunity and inflammation. In this review, we will discuss the role of lipotoxicity associated with positive energy balance during obesity in proinflammatory response in microglia, B and T lymphocytes, and its modulation by neuropeptides.

\section{Introduction}

The first line of defense of an organism before any invasion of pathogens or tissue damage is the innate immune system. It includes physical barriers such as the skin, or specific cell types such as macrophages and complement proteins; as a whole, it modulates the inflammatory response. The inflammatory response consists of an innate cellular system and humoral responses that occur during injury, such as exposure to cold or heat, ischemia, and trauma. The inflammatory response can be divided into two types, depending on the cell type and intensity-duration of the stimulus: (1) acute inflammation, characterized by a time window of minutes to hours and by the abundant presence of neutrophils; (2) chronic inflammation, which in time extends from days up to years, and accumulation of lymphocytes in the inflamed tissue predominates. In this context, precise activation of the inflammatory response is coordinated by the involvement of various cell types including recruitment of macrophages and leukocytes, activation of endothelial cells, platelet aggregation, and release of various cytokines including interleukin 1 (IL-1), interleukin 6 (IL-6), and tumor necrosis factor alpha (TNF- $\alpha$ ). It is through these events that the body physiologically restores the cellular homeostasis and defends the organism from external injuries [1]. However, despite the sophisticated modulation of the inflammatory response in time and space, the chronic release of inflammatory signals promotes the development of diseases such as cancer, hypertension, cardiovascular disorders, and metabolic disorders including diabetes and obesity.

The link between the immune system and the regulation of body energy metabolism has started to be understood in 
the recent years. Initial studies identified selective cellular types for the immune system including pulmonary alveolar macrophages, peritoneal exudate monocytes, and polymorphonuclear leukocytes, which delegate their energy requirement to specific metabolic pathways, depending on the tissue in which they reside. For example, macrophages activate oxidative phosphorylation, whereas monocyte and polymorphonuclear leukocytes are mainly glycolytic [2]. In addition, during an inflammatory event, macrophages increase the catalysis of metabolic enzymes such as hexokinase and citrate synthase in addition to high glucose consumption [3], suggesting an increase in the glycolysis rate during phagocytosis or secretory activity. These studies established the immune system-metabolism relationship in a cellular process called "immunometabolism" [4]. Recently, research has shown that metabolic regulation not only depends on the activation of specific metabolic pathways in a cell type, but that the immune system regulates body metabolism and plays an important role in the development of metabolic disorders such as metabolic syndrome and obesity. Obesity has been characterized as an atypical form of inflammation induced primarily by the accumulation of fatty acids in tissues, altering the metabolic regulation, including liver, adipose tissue, and muscle. This type of inflammation was termed "metainflammation" or "metabolic inflammation" [5].

Positive energy balance during maternal overnutrition or obesity lead to changes in plasma and tissue specific lipidomic profile that might promote inflammation. In fact, saturated lipids have been shown to represent a group of molecules as more active candidates in promoting inflammation through their interaction with toll-like receptors TLR1 and TLR4 and by activating nuclear factor kappa $\mathrm{B}(\mathrm{NF}-\kappa \mathrm{B})$, a promoter of inflammatory genes $[6,7]$. This type of inflammation is not limited to peripheral tissues; it extends to much more distant borders and is able to reach the CNS, promoting the development of neuroinflammation [5]. However, it is also possible that resident brain cells, such as microglia, may induce neuroinflammation independently of their peripheral activation [8]. Paradoxically, modulation of the cytokine-dependent inflammatory signal is controlled by the activation of antagonist cytokines such as IL-10, TGF- $\beta$, IL-11, and agonist receptor IL-1, among other cytokines and interleukin soluble receptors. These cytokines function as anti-inflammatory, inhibiting the activation of macrophages, T lymphocytes, and natural cytotoxic cells (NK) [1]. Recent studies have demonstrated the involvement of molecules produced in the CNS in the regulation of inflammatory and energetic metabolism, proposing that neuropeptides are synthesized by macrophages, lymphocytes, and neutrophils to regulate inflammation and metabolism $[9,10]$. In this review, we will describe the signaling pathways involved in the process of metabolic inflammation in a scenario of positive energy balance and its modulation by neuropeptides.

\section{Lipotoxicity Is a Mediator of Metabolic Inflammation in the CNS}

Epidemiological data confirms a strong link between the increase in the level of obesity and the development of type 2 diabetes, indicating that for every kilogram of gained weight, at the population level, there is a linear increase in the diabetes rate [11]. Experimental evidence, in obese humans and animal models with obesity, suggests that the leakage of lipids from adipose tissue and ectopic accumulation of ceramides (a type of sphingolipid), acylcarnitines, diacylglycerols, and saturated fatty acids cause tissue damage to metabolically relevant organs, including the skeletal muscle, liver, pancreatic beta cells, myocardium, and brain, in an event called lipotoxicity [12-14]. The lipotoxic effect is largely determined because every organ has its own lipid profile. Hence, selective changes in lipid species in different organs may be relevant to the development of lipotoxicity. In this context, it is known that, physiologically, C18:0 type ceramides are essential for cerebellar development and C22:0 and C24:0 ceramides regulate hepatic function $[12,13]$, while saturated diacylglycerols and lipids take part in intracellular signaling processes in many cellular types of the body [14]. In this regard, it has been suggested that, during obesity, new lipid species, which are potentially toxic for the body's organs, are produced, including ceramides, cholesterol, saturated fatty acids, and diacylglycerols. All these species are known to inhibit insulin sensitivity in cellular cultures and animal models [15]. Saturated ceramide and lipid accumulation has even been detected in the skeletal muscle of obese humans, which correlates to insulin resistance [15]. Recent evidence has shown substantial association between lipidomic profile leading to lipotoxicity and activation of neuroinflammation.

Previously, the brain was considered an immunologically privileged organ, partly because the lack of constitutive expression of MHC class I and class II and the absence of classical antigen-presenting cells (APCs) and lymphatic vessels. However, the identification of peripheral immune system cells including $\mathrm{B}$ cells and $\mathrm{T}$ lymphocytes in genetic and nutritional models of obesity has proposed that the metabolic inflammation observed during obesity is able to colonize the CNS and promote central inflammation such as microglia activation [1]. Each of these cell populations will promote an inflammatory state through the secretion of antibodies and interleukins $[16,17]$. We will now describe some of the cell populations that have been implicated in the process of neuroinflammation activation in a lipotoxic context during obesity.

2.1. Microglia. Microglia represent a selective cell type with characteristics of CNS resident macrophages, which originate from erythromyeloid progenitors derived from yolk sac cells during the embryonic stage and which subsequently colonize the brain during embryonic development $[18,19]$. Physiologically, their activation is required for the proper functioning of the CNS as they positively modulate neurogenesis and synaptic plasticity in addition to acting as major APCs in the CNS [20].

The relationship between lipotoxic damage in the context of obesity and the activation of central inflammation is based on evidence showing that the exposure of high fat diet in rodents promotes inflammation in the CNS that culminates as damage to the regions of the hypothalamus, cognitive deterioration, and decreased neurogenesis $[20,21]$. 
Molecularly speaking, it is proposed that, similar to macrophages that regulate innate inflammatory activation in the peripheral system in a lipotoxic context, the activation of microglia in the brain is induced by the interaction of fatty acids with TLRs. In fact, lauric acid (C12:0) and palmitic acid (C16:0) lipids have been identified as inducing TLRs migration to lipid rafts, heterodimerization of TLR1 and TLR2 receptors, and the homodimerization of the TLR4 in macrophages [22, 23]. In addition, experimental evidence has identified the recruitment of the MyD88 protein and $\mathrm{NADPH}$ to these domains correlating with the production of reactive oxygen species (ROS) [22-24]. Our research group has shown that the stimulation of neurons with palmitic acid recruits the inflammatory related serine/threonineprotein kinase TANK-binding kinase 1 (TBK1) to lipid raft domains, which correlates with insulin resistance [25]. These experiments demonstrate that activation of TLR4 participates in the secretion of inflammatory cytokines via the IKK$\mathrm{NF}-\kappa \mathrm{B}$ pathway in microglia, inducing alterations in the hypothalamus and other regions of the CNS $[17,21,26]$, and potentially the recruitment of monocytes from the periphery dependent on the increase of TNF- $\alpha$ [27]. Taken together, exposure of saturated fatty acids favors the interaction and dimerization of TLR1, TLR2, and TLR 4 towards the lipid rafts microdomain, recruitment of NADPH oxidase and MyD88, and production of ROS, where it will be activated in parallel NF- $\kappa \mathrm{B}$ by the IKK and possibly TBK1. Thus, NF- $\kappa$ B-dependent transcriptional activation will promote the secretion of inflammatory cytokines TNF- $\alpha$, IL- $\beta 1$, and IL- 6 and altered metabolic profile, as we have recently proposed [28].

2.2. T Lymphocytes. The role of $\mathrm{T}$ lymphocytes as mediators of metabolic inflammation was initially reported in 2009. Exposure of mice to high fat diet promotes the infiltration of $\mathrm{CD}^{+} \mathrm{T}$ lymphocytes into adipose tissue favoring the infiltration of M1 macrophages with inflammatory profile and generating insulin resistance, while its inactivation by specific antibodies represses this phenomenon [29]. Inflammatory activation in the adipose tissue of obese mice is potentiated by two possible scenarios: (1) by reducing expression of the transcriptional factor Foxp3 in $\mathrm{T}_{\text {reg }}$ lymphocytes [30], cells responsible for regulating the inflammatory response and suppressing autoimmune reactions [31] and (2) by activating a proinflammatory subtype of $\mathrm{CD} 4^{+} \mathrm{T}$ helper cells called Th1 [32]. Activation of these molecular pathways have been widely identified in the generation of insulin resistance and type 2 diabetes mellitus in obese subjects. In fact, it has been proposed that the activation of $\mathrm{T}$ lymphocytes in adipose tissue is a key event and depends on the presentation of antigens by MHC class II in $\mathrm{CD} 4^{+} \mathrm{T}$ cells and a costimulatory signal [27]. This mechanism has been described to promote the synthesis of IL-2, where additional interaction of TRCMHCII is required for the activation of the coreceptor CD28. Also, the TRC-MHCII interaction recruits the Zap70 protein to the $\mathrm{CD} 3$ coreceptor allowing the activation of the PLC $\gamma$-PIP2-PKC $\theta$ cascade, downstream activation of ERK, and c-Fos expression. On the other hand, the CD28 coreceptor via the PI3K pathway activates MEKK and JNK allowing the production of c-jun. Both TCR and CD28 lead to the transcriptional factor AP-1 nuclear translocation, inducing the expression of IL-2 [31]. In addition, the TCR$\mathrm{CD} 28$ binomial in $\mathrm{CD}^{+} \mathrm{T}$ lymphocytes promotes $\mathrm{PKC} \theta$ to activate the CARMA1-Bcl10-MALT1 complex by inducing the activation of NF- $\kappa \mathrm{B}$ and TBK1 and the proliferation, differentiation, and production of IL-2, dependent on AP-1 $[33,34]$. Thus, in a lipotoxic context, we might suggest that the interaction of $\mathrm{CD}^{+}{ }^{+} \mathrm{T}$ lymphocytes with an antigenpresenting cell would allow differentiation towards the Th1 subtype by altering the $T h 1 / \mathrm{T}_{\text {reg }}$ ratio towards proinflammatory, interferon-producing (INF- $\gamma$ ) T cells, IL-2, and TNF- $\alpha$ and decreased IL-10 production activity of $\mathrm{T}_{\text {reg }}$ cells. All this would allow the polarization of macrophages to the M1 phenotype producing proinflammatory cytokines TNF- $\beta$, IL- $1 \beta$, and IL-6. On the other hand, TCR-MHCI interaction by $\mathrm{CD} 8^{+} \mathrm{T}$ lymphocytes could secrete MCP1 exacerbating the recruitment of macrophages to adipose tissue and increasing inflammation.

Activation and recruitment of lymphocytes to adipose tissue during positive energy balance in obesity also cause them to migrate to more distant borders and interact with CNS cells, including microglia, as described for various pathologies such as experimental autoimmune encephalomyelitis and cerebral ischemia $[33,35]$. In a summarized way they involve the attraction of $\mathrm{T}$ cells to the site inflamed by chemokine such as Interferon-Inducible T-Cell Alpha-Chemoattractant (I-TAC), interferon gamma-induced protein 10 (IP-10), and monokine induced by gamma interferon (MIG) [36], expression of the E and P selectins in endothelial cells that serve as anchor for their ligands in Tlymphocytes, PSGL1 , and $\alpha 4$-integrin, facilitating the transport of lymphocytes through blood vessels (Figure 1). Finally, the ultimate barrier for the invasion of $\mathrm{T}$ lymphocytes into the nervous system is represented by the blood-brain barrier (BBB), which, by expressing the LFA-1 membrane protein in T cells, can bind to the ICAM-1 protein endothelial cells and cross the $\mathrm{BBB}$ leaving morphologically intact narrow junctions. This has been corroborated in recent studies, showing the inhibition of the expression of these adhesion proteins, reducing the infiltration of $\mathrm{T}$ lymphocytes into the brain during an inflammatory event $[37,38]$, which is presumably regulated by poly(ADP-ribose) polymerase-1 (PARP) [38]. Despite the evidence supporting the infiltration of $\mathrm{T}$ lymphocytes into the nervous system, molecular and cellular mediators that mediated the communication between the brain and the immune system remained unidentified. Maybe the first evidence to support CNS-peripheral immune system cross-talk was recently identified by showing that selective inflammatory stimulus (IL-1 $\beta$ ) into the CNS and astrocytes secrete extracellular vesicles (EV), which cross the BBB and reach organs such as the liver allowing the suppression of PPAR $\alpha$ and favoring the production of TNF- $\alpha$ and IL- $\beta 1$ and monocyte chemoattractant protein-1 (MCP-1). Cytokines production promotes the $\mathrm{T}$ lymphocytes recruitment into the inflamed brain region [39] (Figure 1).

2.3. B Lymphocytes. B lymphocytes represent a cell type of the immune system, originating from hematopoietic cells 


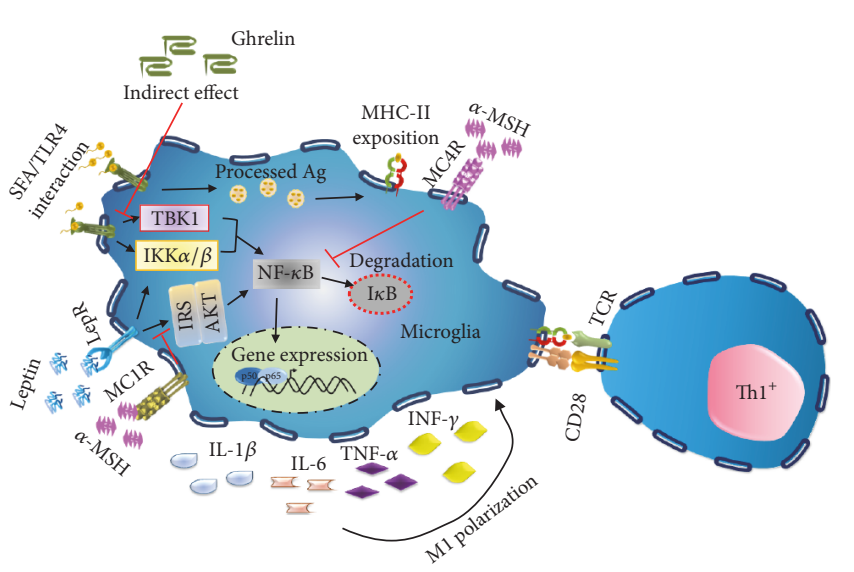

(a)

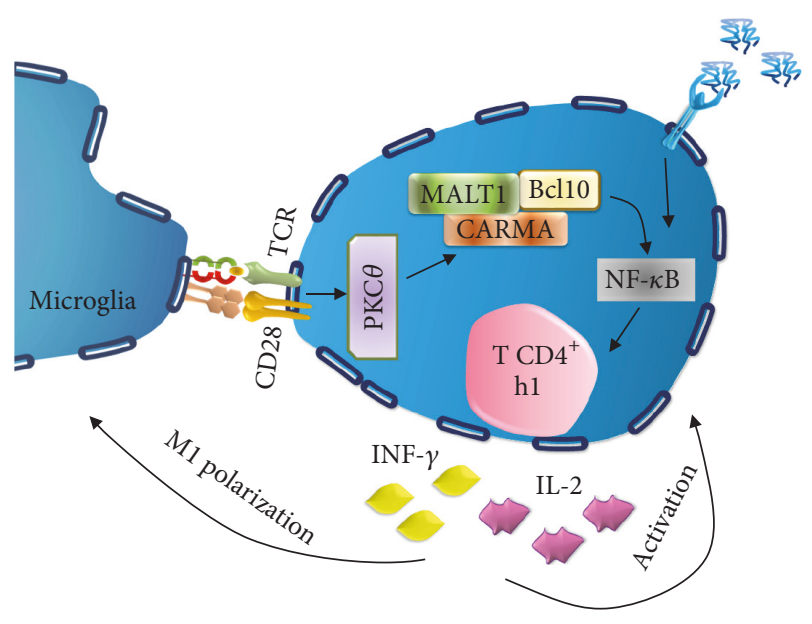

(b)

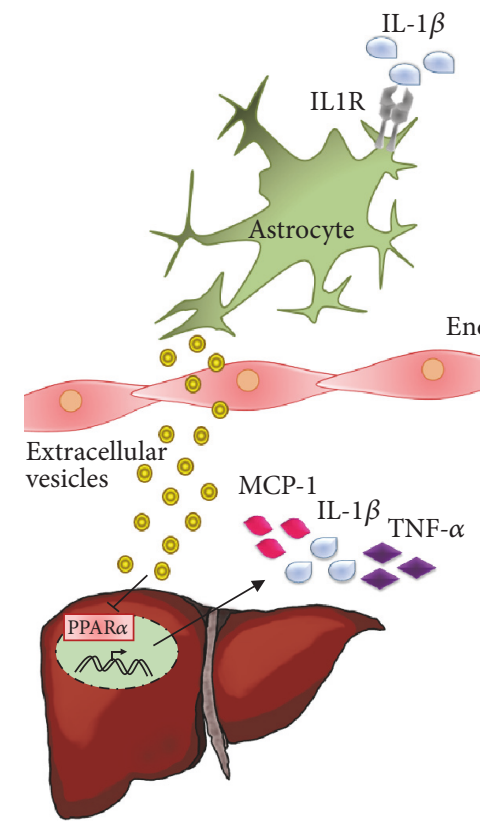

(c)
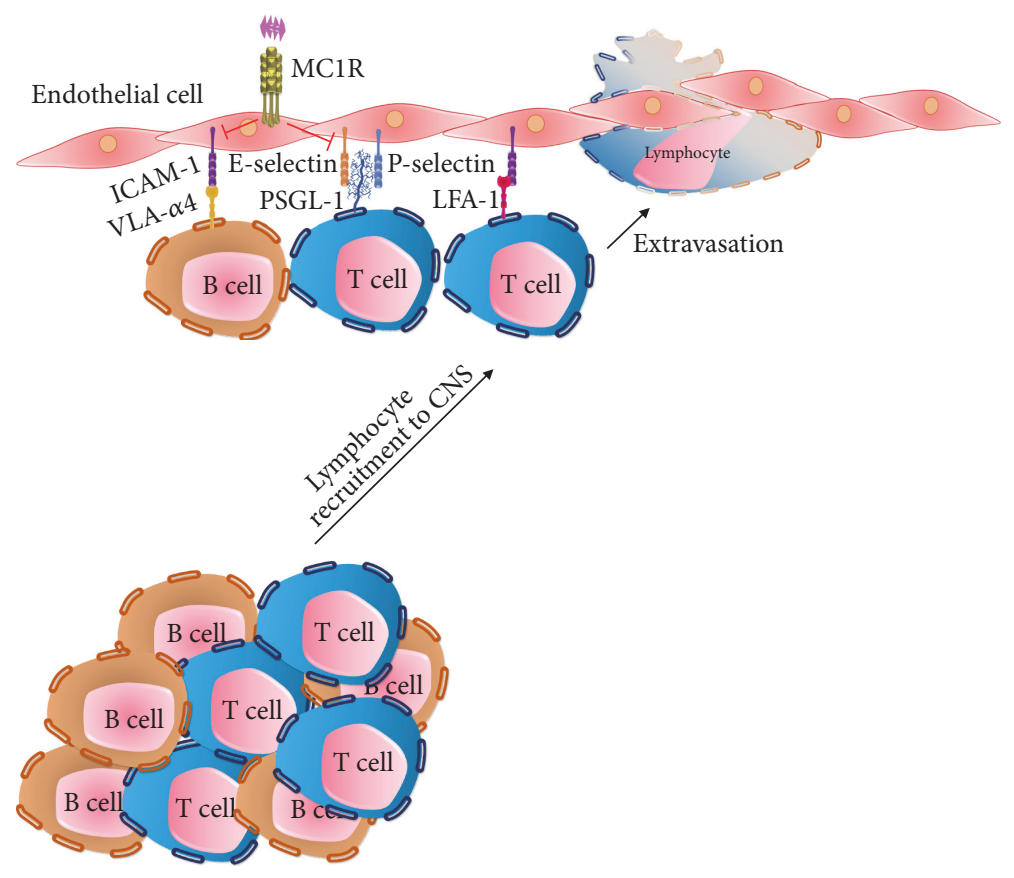

(d)

\begin{tabular}{|c|c|c|c|c|c|c|c|}
\hline$<$ TNF- $\alpha$ & 业 & $\alpha-\mathrm{MSH}$ & $P$ & TCR & E-selectin & \{ & TLR4 \\
\hline$\sum$ IL-6 & 0 & INF- $\gamma$ & : & MC1R & P-selectin & $\S$ & $\begin{array}{l}\text { MHC } \\
\text { class II }\end{array}$ \\
\hline IL- $1 \beta$ & 0 & MCP-1 & 贸 & MC4R & PSGL-1 & 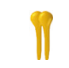 & $\mathrm{CD} 28$ \\
\hline SFA & $\psi$ & LepR & 雨 & Leptin & VLA- $\alpha 4$ & $\longrightarrow$ & Proinflammatory \\
\hline IL-2 & $y$ & IL1R & 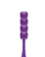 & ICAM-1 & LFA-1 & $\longrightarrow$ & Anti-inflammatory \\
\hline
\end{tabular}

FIGURE 1: Immunomodulatory mechanism exerted by neuropeptides in microglia exposed to a lipotoxic stimuli. (a) Microglia pro- and antiinflammatory stimuli. In microglia, fatty acids and leptin can induce cytokine secretion through TLR4/IKK/NF- $\kappa \mathrm{B}$ pathway, but only leptin can activate NF- $\kappa$ B through LepR/IRS1/AKT pathway. Also, leptin induces MHC class II expression leading to T lymphocytes activation. Cytokines have paracrine and autocrine effects. $\alpha$-MSH inhibits the I $\kappa \mathrm{B}$ degradation through MC4R and by blocking the LepR pathway through MC1R. Ghrelin blocks the TLR4/IKK/NF- $\kappa$ B pathway activation in microglia cells by indirect effects. (b) T lymphocyte activation. Microglia presents the antigen to CD4+ T cells and through the receptor complex MHCII/B7-TCR/CD28 these cells proliferate to the proinflammatory phenotype Th1 which produce IL- 2 and INF- $\gamma$ through PKC $\theta$-CARMA-MALT1-Bcl10/NF- $\kappa$ B complex and by leptin action. (c) Astrocytes inflammatory mechanism. IL-1 $\beta$ induces the secretion of extracellular vesicles which inhibits PPAR $\alpha$ expression on hepatocytes leading to TNF- $\alpha$, IL-1 $\beta$, and MCP-1 production facilitating lymphocyte infiltration to CNS. (d) Lymphocyte extravasation to CNS. Inflammatory signals such as cytokines and CMP-1 promote the expression of adhesion proteins E-selectin, P-selectin, and ICAM1. Lymphocytes can interact with the adhesion proteins through its own integral proteins VLA- $\alpha 4$, PSGL-1, and LFA- 1 and cross the BBB. Melanocortins prevent T-cell infiltration by the $\alpha$-MSH-MC1R interaction which blocks externalization of adhesion proteins. 
that mature in bone marrow and participate in innate and adaptive immunity. Their main function is the production of antibodies against foreign antigens into the body [40]. In addition, they also function as APCs by presenting the antigens to $\mathrm{T}$ lymphocytes that were initially captured by their B-cell receptor and promote inflammation by secreting proinflammatory cytokines such as IL- 6 and TNF- $\alpha$, thus favoring the polarization of $\mathrm{T}$ cells into a proinflammatory phenotype [40]. The molecular mechanisms that promote the migration of B lymphocytes to the CNS are not yet fully understood; however, it has been proposed that its association with membrane proteins, such as the $\alpha-4$ subunit of VLAA, ICAM-1, and ALCAM, allows passage through the BBB $[41,42]$.

Unlike the role of macrophages and Th1 lymphocytes in the modulation of metabolic inflammation during obesity, the impact of B lymphocytes in this context has not yet been fully understood [43]. However, there are several reports that justify its presence and potential participation in the modulation of inflammation at the CNS level. In the first instance, B lymphocytes possess TLR capable of responding to microbial antigens in a $\mathrm{T}$ lymphocyte-dependent manner [44], which have been identified to actively mediate metabolic inflammation by interacting with fatty acids [23, 26]. In fact, the accumulation of antibodies of the IgG class in the microglia of the ARC nucleus has been observed in mice exposed to a hypercaloric diet, polarizing it towards the M1 phenotype through its Fc receptor [45]. B lymphocytes itself from obese mice might produce a proinflammatory IgGc class which, when administered to mice deficient in B cells, increases the production of proinflammatory cytokines, the polarization of M1 macrophages, and the activation of $\mathrm{T}$ lymphocytes [16]. These studies confirm that the function of $B$ lymphocytes in a metabolic compromise scenario seems to be deleterious and promotes metabolic inflammation, leading to the belief that its inhibition could prevent this mechanism. Experimental data demonstrate that this hypothesis is partially true, since the elimination of $\mathrm{B}$ lymphocytes using a CD20-specific antibody in a murine model of obesity induced by high fat diet improved glucose tolerance, reduced insulin levels, and reduced the inflammatory profile in adipose tissue. However, the total elimination of B and T lymphocyte populations has no effect [46]. In this scenario, defects in Bcell function have been reported in situations of metabolic compromise as presented in diabetic and nondiabetic obese patients. Subjects with this metabolic profile show a low response to antibodies and secrete a greater amount of IL6 and TNF- $\alpha$ than healthy subjects, and only obese and diabetic patients have a decrease in the production of IL-10, a key cytokine in the suppression of the immune response mediated by B cells $[37,47]$. In this way, it is possible that, in a lipotoxic context, the interaction of B lymphocytes with fatty acids or their recruitment to the CNS by glial cells [48] plays a key role in metabolic inflammation, through secretion of inflammatory cytokines, the activation of $\mathrm{CD}^{+}$ $\mathrm{T}$ lymphocytes, and microglia polarization towards the M1 phenotype, through MHC class II mediated antigen presentation and the $\mathrm{Fc}$ fraction of the antibodies, respectively (Figure 1).

\section{Energy-Sensing Hormones and Neuropeptides Modulate Central Inflammation}

Neuropeptides are small molecules composed of amino acids, produced mainly but not exclusively by cells of the nervous system, and regulate important physiological processes, including reproduction, feeding, regulation of body weight, memory, anxiety, mood, excitement, reward, and sleep/wake stages [49]. Anti-inflammatory properties of various neuropeptides have been identified in the context of positive energy balance, which include alpha-melanocyte-stimulating hormone (MSH- $\alpha$ ), vasoactive intestinal peptide (VIP), and neuropeptide Y (NPY) $[10,50,51]$. There is also evidence of the involvement of hormonal signals dependent on ghrelin and leptin on the modulation of an anti-inflammatory phenotype in microglia $[49,52]$. In the next section, we will describe evidence of the involvement of peptides derived from prohormone proopiomelanocortin (POMC) and the ghrelin and leptin hormones as potential central modulators of microglia-dependent inflammation in a context of positive energy balance.

3.1. Peptides Derived from POMC. Melanocortins are posttranslational products of the POMC gene which is expressed in the arcuate nucleus (Arc) of the hypothalamus, from which a family of opioids and melanocortins products are synthetized including $\beta$-endorphin, adrenocorticotropic hormone (ACTH), and the melanocyte stimulating $\alpha, \beta$, and $\gamma$ hormones (MSH). This neuropeptide system is unique since its regulation depends on two small endogenous proteins, the peptide-like agouti and the $Y$ neuropeptide $[53,54]$.

The ability of melanocortins as anti-inflammatory agents is well documented in different models of peripheral inflammation [55]. Melanocortins exert their action through their interaction with the MCIR receptor located in immune cells innate neutrophils, macrophages, and dendritic cells also in microglia, in addition to possessing a high affinity towards MSH- $\alpha$. The administration of MSH- $\alpha$ has shown to reduce the production of IL-1, IL- 6 , and TNF- $\alpha$, and monocyte receptor expression is upregulated in the presence of stimuli such as lipopolysaccharides (LPS) or cytokines. At the CNS, systemic administration of MSH- $\alpha$ has been reported to reduce cytokine expression during cerebral ischemia and decrease inflammation at the hippocampal level by inhibiting LPS or IL-1 $\beta$ induced dinoprostone (PGE2) secretion. MSH- $\alpha$ also reduces the production of nitric oxide (NO) and prostaglandin (PG) favored by IL- $1 \beta$ in the hypothalamus of rats [56]. In the past decade, MC3R and MC4R receptors have been proposed as responsible for the anti-inflammatory action of melanocortins in the brain. This proposal is based on studies demonstrating that the expression of these two receptors is higher in comparison to the other members of this group [57] and that the administration of MSH- $\alpha$ reduces the hypothalamic production of iNOS and COX2 in rats administered with LPS and decreases the expression of TNF- $\alpha$ induced by LPS and INF- $\gamma$ in neurons expressing the MC4R, whose effect is blocked by the administration of the MC4R antagonist [58]. 
Scientific evidence suggests that melanocortins exert their anti-inflammatory activity by inhibiting the transcription factor NF- $\kappa \mathrm{B}$ [59] and by inducing IL-10 in microglia through the $\mathrm{MC} 4 \mathrm{R}$ receptor. In astrocytes, both brain-derived neurotrophic factor (BDNF) and peroxisomeproliferator-activated receptor gamma (PPAR $\gamma)$ expression have been observed to be regulated by the MC4R-cAMPPKA-CREB pathway [60]. On the other hand, activation of the MC1R receptor using the pharmacological agonists MS05 and MS09 is able to reduce the expression of Eselectin and VCAM, in addition to reducing the activation of NF- $\kappa \mathrm{B}$ in endothelial cells exposed to TNF- $\alpha$. Knowing that E-selectin and VCAM represent integral membrane proteins important for the migration of $\mathrm{B}$ and $\mathrm{T}$ lymphocytes towards the site of inflammation [41], it is proposed that the blockade of the extravasation of these cells represents an anti-inflammatory mechanism parallel to that described by melanocortins. Finally, there are reports that have shown that activation of the MCIR receptor represses the leptindependent inflammation in a lipotoxic context [61, 62]. Thus, it is tentative to propose that, in a lipotoxic scenario, melanocortins block the inflammatory process by four main events: (1) increase the secretion of IL-10 from the microglia, (2) decrease the activation of NF- $\kappa \mathrm{B}$, (3) block the action proinflammatory effects of leptin, and (4) prevent infiltration of lymphocytes through the BBB to the CNS.

3.2. Ghrelin. It is a peptide of 28 amino acids secreted mainly by the stomach and duodenum, although it is also produced by neurons in the arcuate nucleus [63]. However, overproduction of ghrelin in the hypothalamus promotes food consumption and increases body weight [64]. Ghrelin seems to induce acute peripheral insulin resistance independent of growth hormone $(\mathrm{GH})$, cortisol, and basal serum free fatty acids [65] and both insulin and ghrelin exert regulatory effects on each other $[66,67]$. Two types of ghrelin, des-acylghrelin (DAG) and acyl-ghrelin (AG), are known to regulate food intake and growth hormone secretion and influence glucose homeostasis, neuroprotection, memory, immunity, and neuroinflammation $[63,68]$. Its main function is to act as an orexigenic signal by antagonizing the effects of leptin via the NPY/Y $\mathrm{Y}_{1}$ axis, through its interaction with the growth hormone secretagogues receptor (GHSR) in NPY and AgRP neurons.

Obesity is known to promote an imbalance in the hormonal profile of obese individuals. Changes in the AG/DAG ratio in obese and metabolic abnormal Italian children compared with normal weight children have been reported [69]. The authors found a $81 \%$ increase in AG in obese and metabolic abnormal children when compared with healthy children [69]. Also, recently it has been documented that AG concentrations are higher in plasma of obese patients (435 pg/mL) than nonobese patients $(167 \mathrm{pg} / \mathrm{mL})$ [70]. Although it has been stated that during obesity ghrelin plasma levels are decreased in obese individuals as a compensatory mechanism to reduce appetite $[71,72]$, it only refers to total ghrelin in plasma, given that AG depicts $10 \%$ of total ghrelin. In this context, decreasing levels of this hormone may be potentially related to a decrease in DAG concentration [70].
In fact, diet induced obesity (DIO) in mice by high fat diet exposure leads to $15 \%$ increase in preproghrelin mRNAproducing cells than control [73]. In addition, both DIO and ob/ob mice model had normal plasma levels of ghrelin which correlates with a decrease in DAG plasma levels [73]. It is known that DAG is metabolized to AG by action of the ghrelin O-acyltransferase (GOAT); not only does the importance of this enzyme lie in its ability to acetylate the unacetylated form of ghrelin, but it has been reported that knocking down the GOAT gene protects mice from obesity induced diet, improves insulin sensitivity, and reduces adiposity when fed HFD and high glucose diet [74]. Furthermore, there is a positive correlation between body mass index (BMI) and GOAT concentration in obese patients, where BMI $>50$ had increased concentrations (+34\%) compared with normal weight controls [75]. These evidences suggest that an alteration in the AG/DAG ratio related to GOAT activity is potentially important to contribute to metabolic alterations observed during obesity and diabetes. This proposal is tested in recent reports showing that decreasing AG plasma levels associates with positive effects in metabolic disorders, such as decreasing postprandial glucose levels and improvement of insulin sensitivity in overweight patients with type 2 diabetes $[76,77]$.

On the other hand, the anti-inflammatory and neuroprotective properties of ghrelin have been demonstrated in experimental cord injury (SCI) models, where the administration of ghrelin inhibits the activation of the p38 AMPK/NF- $\kappa \mathrm{B}$ pathway followed by the release of the factor of nerve growth (proNGF). These data were corroborated in in vitro models showing that ghrelin stimulation prevented the activation of the AMPK and JUN signaling pathway in addition to reducing the production of ROS in microglia stimulated with LPS [78]. Other studies demonstrated that the intracerebroventricular administration of ghrelin reduces the mRNA expression of the proinflammatory cytokines IL$1 \beta$, IL- 6 , TNF- $\alpha$, INF- $\gamma$, and iNOS in the blood of rats subjected to a $70 \%$ calorie restriction by one week [79]. However, it appears that this mechanism is independent of the GHSR $1 \alpha$ receptor, since this receptor is not expressed in the resident microglia of the brain and spinal cord or in primary culture. In this context, ghrelin might potentially act by blocking the expression of the matrix metalloproteinase 3 (MMP-3) on dopaminergic stressed cells [80]. In addition to this, ghrelin has been proposed as a neuroprotective agent by decreasing the production of proinflammatory cytokines, IL-1 $\beta$, IL-6, TNF- $\alpha$, iNOS, and ROS, by microglia in models of amyotrophic lateral sclerosis, neurotoxicity, neuronal death induced by kainic acid, experimental autoimmune encephalomyelitis, Parkinson's, and Alzheimer's [49, 81]. In addition, it blocks the activation of the microglia and reduces infiltration of $\mathrm{T}$ lymphocytes towards the spinal cord against a challenge with LPS [78, 82]. Ghrelin also prevents the differentiation of a proinflammatory T-cell subtype, termed Th17, by blocking the activation of the mTOR/STAT3 pathway [83]. In relation to diseases closely related to metabolism, ghrelin has been linked to attenuation in the activation of the TLR4/MyD88/TRAF6/NF- $\kappa$ B pathway and cell death in pheochromocytoma cells (PC12) in a model of diabetic 


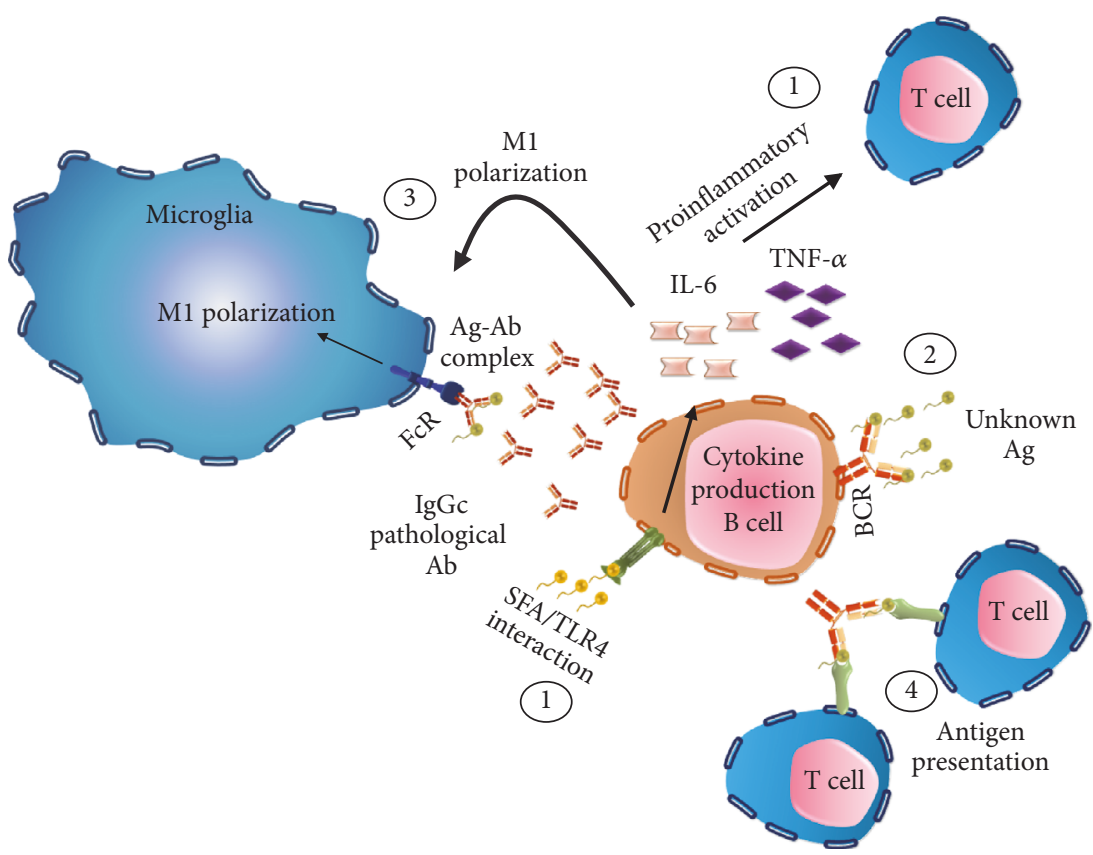

FIGURE 2: B lymphocytes regulate neuroinflammation. (1) Saturated fatty acids induce the secretion of proinflammatory cytokine through the interaction with the TLR4 located in B lymphocytes, favoring the polarization of lymphocytes and microglia activation to a proinflammatory phenotype. (2) Production of a pathogenic IgG class antibody (Ab) regulated by an unknown antigen (Ag). (3) Microglia M1 polarization trough the $\mathrm{Ab}-\mathrm{Fc}$ receptor interaction. (4) B cells receptor (BCR) mediated antigen presentation.

encephalopathy [84]. Taken together, these data allow us to hypothesize that ghrelin plays an important role in the regulation of metabolic inflammation in the CNS by modulating the secretion of proinflammatory cytokines by microglia.

3.3. Leptin. Leptin is a peptide hormone with a molecular structure similar to interleukins, composed of 146 amino acids, its synthesis is primarily in adipocytes, and it travels through the circulation to reach the CNS, where it interacts with the leptin receptor (LepR) located in hypothalamic neurons and regulates food intake through an anorexigenic signal [85]. It is also involved in hematopoiesis, angiogenesis, and glucose metabolism and has a proven role in cells innate and adaptive immune system [85]. In normal human patients, leptin plasma levels are around $21.6 \mathrm{pg} / \mathrm{mL}$, whereas obese patients show higher concentrations $(61.9 \mathrm{pg} / \mathrm{mL})[70]$ Experimental data show that the LepR has the ability to activate signaling pathways associated with inflammatory profiles including those of IL-6, the JAK-STAT, and MAPKPI3K pathway, regulates the production of IL-2 and INF$\gamma$ in Thl lymphocytes, and reduces the production of antiinflammatory IL-10 cytokine [86]. Furthermore, it appears that leptin and swelling ratio is positive feedback type as systemic injection of LPS to mice increases the concentration of mRNA in adipose tissue leptin mice and induces the secretion of IL- $1 \beta$; besides TNF- $\alpha$ and IL- 1 cytokines regulate the expression of leptin. Additionally, the inflammatory effect exerted by leptin is dependent on modulation at the level of adhesion molecules expression such as ICAM-1 and VLA2 in $\mathrm{CD}^{+}$cells, preventing proliferation of suppressor cells of the immune response type $\mathrm{T}_{\text {reg }}$ Foxp3 [31, 87]. The role of this hormone on the proinflammatory action of B lymphocytes seems limited to increase phosphorylation STAT3, a crucial mechanism in the production of TNF- $\alpha$, accompanied by low phosphorylation in AMPK, crucial for the activation of E47 through phosphorylation of p38 AMPK; and inhibiting apoptosis in a mice model exposed to HFD [88]. The proinflammatory effects of leptin on microglia are by nature proinflammatory and induce secretion of IL- $1 \beta$ cytokine-dependent stimulation with LPS, by a mechanism independent caspase 1, IL- 6 by the pathway IRS1-PI3K-AKTNF-kB and TNF- $\alpha$, and CINC-1 MIP-2 chemokines [89]. In fact, IL- 6 has proved to have a sensitizing action to leptin in hypothalamic neurons in obese animals by exposure to high fat diet [90]. It has been observed that in microglia deficient mouse leptin (ob/ob) there is a downregulation in genes integrin-alpha X (Iigax), NALP3, and molecule F4/80, important for correct development of the inflammatory response and T-cell differentiation regulated by APC [91] (Figure 2).

\section{Potential Treatments for Inflammation in Metabolic Related-Diseases}

Obesity is a worldwide health problem showing failure in pharmacologic and therapeutic interventions to ameliorate its metabolic complications. Diet might show the first potential avenue to modulate this pandemic. It is widely reported that polyunsaturated fatty acids (PUFAs) had beneficial effects on several metabolic related-diseases, such as obesity. For instance, omega- 3 fatty acids ( $\omega$-3 PUFAs) inhibit mammary tumor progression in obese mice [92], like wise 
this fatty acids has anti-inflammatory effects in the adipose tissue and hypothalamus $[93,94]$, and protect against insulin resistance and dyslipidemia by suppressing the activation of TLR4 $[95,96]$. The key receptors involve in this beneficial effects are the G protein-coupled receptor (GRP), specifically the selective GRP40 and GRP120, which has been proposed has possible therapeutic targets for insulin resistance and metabolic inflammation [97, 98]. In fact, administration of a GRP40 agonist (Yhhu4488) promotes high expression of glucagon-like peptide-1 (GLP-1), decreased fasting blood glucose level, improved $\beta$-cell function and lipid homeostasis in type 2 diabetic ob/ob mice [99]. Also, GRP120 stimulation by a selective agonist improved glucose tolerance, decreased hyperinsulinemia, increased insulin sensitivity and decreased hepatic steatosis in a DIO mice model [100]. Of note, the role of GRP40 and GRP120 might be potentially relevant given that both show high expression within the hypothalamus and the combined activation of both receptors results in better metabolic outcomes [98].

Another possible neuroinmmunometabolic target are the kinases TBK1 and IKKE related to inflammatory pathways. These proteins had been reported to participated in the development of insulin resistance and diabetes $[25,101]$. In addition, we proposed recently that TBK1 may have a significant role in the microglia-mediated neuroinflammation observe during obesity [28]. In fact, it has been demonstrated that the administration of an specific TBK1-IKKe inhibitor (amlexanox), reduces weight, insulin resistance, fatty liver and inflammation, as well as increased energy expenditure [102]. Together, these data suggest that dual-specificity inhibitors of IKKe and TBK1 may be effective therapies for metabolic disease in an identifiable subset of human patients [103].

Finally, the ghrelin system might represent another possible molecular target for immunomodulation. The administration of des-acyl-ghrelin analog (AZP531) prevent dysregulation of glucose homeostasis in C57BL/6J mice exposed to a HFD [104]. Furthermore, chronic exposure to an inhibitor of AG secretion (CF801) decreased weight gain and adiposity without affecting caloric intake [105]. More recently, a synthetic triterpenoids has been proposed as a potential therapeutic agent to treat diabetes and obesity., due to its ability to inhibit ghrelin acylation by the human isoform of GOAT (hGOAT), these compounds function as covalent reversible inhibitors of hGOAT [106]. Thus, blocking proinflammatory signals through GRPs or nuclear factors inhibitor such as TBK1, and reducing AG plasma levels, might be potential pharmacologic treatments to obesity and metabolic disorders.

\section{Conclusions}

We contemplate that the activation inflammation associated central lipotoxicity in a scenario of positive energy balance is dependent on time and intensity of the stimulus. At early times of ingestion of a high fat diet, lipids interact with toll-like receptors (SFA-TLR4) activating inflammatory pathway MyD88/IKK/NF- $\kappa$ B and possibly the TBK1 protein, initiating secretion of proinflammatory cytokines
IL-1 $\beta$, IL-6, TNF- $\alpha$ and INF- $\gamma$. Meanwhile, in a parallel scenario, increased inflammation at the level of adipose tissue promotes increased concentration of leptin in the plasma and by promoting the expression of adhesion proteins on the cells of the BBB, as ICAM-1, VLA-2 and ALCAM, cells might recruit peripheral immune into the CNS by the action of IL- $1 \beta$. In particular, leptin increase might sensitize microglia subsequent to proinflammatory stimuli and will induce expression of MHC class II and expression of IL-1 $\beta$. At late, cells such as B and T lymphocytes and macrophages could infiltrate the CNS, where microglia would serve as an APC cell to T-cell and by TCR-CD28/MHCII interaction, might recruit the complex CARMA1-Bcl10 -MALT1, allowing activation NF-kB and IL-2 secretion. In this state T cells could be placed in a state of Th1 type secreting cell or inflammatory cytokines. Likewise, a reduction would be expected in the production of IL-10 because of the action of the INF- $\gamma$ and SFA on $\mathrm{T}_{\text {reg }}$ cells. B cells attracted to the CNS begin producing IgG toxic antibodies that will accumulate within microglia and will be able to act as ACP with T cells. This intricate network of cells and cytokines form a positive feedback loop that amplifies the effect initiated by increasing dietary lipids. At this level, neuropeptides as ghrelin and POMC may represent potential modulators of inflammation based on their characteristic of being anti-inflammatory. Ghrelin can block the TLR4/MyD88/TRAF6/NF-KB pathway activated in microglia by SFA and decrease the activity of the AMPK and JUN, important for the production of IL-2. POMC derived peptides attenuate secretion of proinflammatory cytokines via MC4R-cAMP-PKA-CREB, which induces the release of IL-10. While MC1R receptor activation reduces the expression of the adhesion proteins E-selectin and VCAM, and reduce the activation of $\mathrm{NF}-\mathrm{kB}$ in endothelial cells exposed to TNF- $\alpha$ (Figure 2). Overall, neuropeptides in the CNS modulate inflammation and migration of peripheral cells into the CNS via the BBB and may represent a molecular node during positive energy balance as is the obesity and maternal overnutrition.

\section{Conflicts of Interest}

The authors declare no conflicts of interest.

\section{Acknowledgments}

The authors thank Dr. Sergio Lozano from Scientific Publications Support, Faculty of Medicine, Autonomous University of Nuevo Leon, for reading and commenting on the manuscript. This work was funded by National Council of Science and Technology in Mexico (CONACYT) (255317 and 261420) and ISN CAEN Award for Alberto Camacho.

\section{References}

[1] L. Ciaccia, Fundamentals of Inflammation, Cambridge University Press, 2010.

[2] R. Oren, A. E. Farnham, K. Saito, E. Milofsky, and M. L. Karnovsky, "Metabolic patterns in three types of phagocytizing cells," The Journal of Cell Biology, vol. 17, pp. 487-501, 1963. 
[3] P. Newsholme, R. Curi, S. Gordon, and E. A. Newsholme, "Metabolism of glucose, glutamine, long-chain fatty acids and ketone bodies by murine macrophages," Biochemical Journal, vol. 239, no. 1, pp. 121-125, 1986.

[4] L. A. J. O’Neill, R. J. Kishton, and J. Rathmell, “A guide to immunometabolism for immunologists," Nature Reviews Immunology, vol. 16, no. 9, pp. 553-565, 2016.

[5] C. Han, M. Rice, and D. Cai, "Neuroinflammatory and autonomic mechanisms in diabetes and hypertension," American Journal of Physiology - Endocrinology and Metabolism, vol. 311, no. 1, pp. E32-E41, 2016.

[6] P. C. Calder, "N-3 Fatty acids, inflammation and immunity: new mechanisms to explain old actions," Proceedings of the Nutrition Society, vol. 72, no. 3, pp. 326-336, 2013.

[7] L. A. J. O’Neill and D. Grahame Hardie, "Metabolism of inflammation limited by AMPK and pseudo-starvation," Nature, vol. 493, no. 7432, pp. 346-355, 2013.

[8] J. P. Thaler, C.-X. Yi, E. A. Schur et al., "Obesity is associated with hypothalamic injury in rodents and humans," The Journal of Clinical Investigation, vol. 122, no. 1, pp. 153-162, 2012.

[9] E. M. Sternberg, "Neural regulation of innate immunity: a coordinated nonspecific host response to pathogens," Nature Reviews Immunology, vol. 6, no. 4, pp. 318-328, 2006.

[10] E. Gonzalez-Rey and M. Delgado, "Vasoactive intestinal peptide inhibits cycloxygenase- 2 expression in activated macrophages, microglia, and dendritic cells," Brain, Behavior, and Immunity, vol. 22, no. 1, pp. 35-41, 2008.

[11] G. Eknoyan, "Adolphe quetelet (1796-1874) - the average man and indices of obesity," Nephrology Dialysis Transplantation, vol. 23, no. 1, pp. 47-51, 2008.

[12] C. Ginkel, D. Hartmann, K. Vom Dorp et al., "Ablation of neuronal ceramide synthase 1 in mice decreases ganglioside levels and expression of myelin-associated glycoprotein in oligodendrocytes," Journal of Biological Chemistry, vol. 287, no. 50, pp. 41888-41902, 2012.

[13] Y. Pewzner-Jung, O. Brenner, S. Braun et al., "A critical role for ceramide synthase 2 in liver homeostasis II. Insights into molecular changes leading to hepatopathy," Journal of Biological Chemistry, vol. 285, no. 14, pp. 10911-10923, 2010.

[14] M. Chakraborty and X.-C. Jiang, "Sphingomyelin and its role in cellular signaling," Advances in Experimental Medicine and Biology, vol. 991, pp. 1-14, 2013.

[15] M. E. Ertunc and G. S. Hotamisligil, "Lipid signaling and lipotoxicity in metaflammation: indications for metabolic disease pathogenesis and treatment," Journal of Lipid Research, vol. 57, no. 12, pp. 2099-2114, 2016.

[16] D. A. Winer, S. Winer, L. Shen et al., "B cells promote insulin resistance through modulation of $\mathrm{T}$ cells and production of pathogenic IgG antibodies," Nature Medicine, vol. 17, no. 5, pp. 610-617, 2011.

[17] T. Maric, B. Woodside, and G. N. Luheshi, "The effects of dietary saturated fat on basal hypothalamic neuroinflammation in rats," Brain, Behavior, and Immunity, vol. 36, pp. 35-45, 2014.

[18] K. Kierdorf, D. Erny, T. Goldmann et al., "Microglia emerge from erythromyeloid precursors via Pu.1-and Irf8-dependent pathways," Nature Neuroscience, vol. 16, no. 3, pp. 273-280, 2013.

[19] F. Alliot, I. Godin, and B. Pessac, "Microglia derive from progenitors, originating from the yolk sac, and which proliferate in the brain," Developmental Brain Research, vol. 117, no. 2, pp. 145-152, 1999.
[20] D. P. Schafer and B. Stevens, "Microglia function in central nervous system development and plasticity," Cold Spring Harbor Perspectives in Biology, vol. 7, no. 10, Article ID a020545, 2015.

[21] M. Valdearcos, M. M. Robblee, D. I. Benjamin, D. K. Nomura, A. W. Xu, and S. K. Koliwad, "Microglia dictate the impact of saturated fat consumption on hypothalamic inflammation and neuronal function," Cell Reports, vol. 9, no. 6, pp. 2124-2139, 2014.

[22] S. W. Wong, M.-J. Kwon, A. M. K. Choi, H.-P. Kim, K. Nakahira, and D. H. Hwang, "Fatty acids modulate toll-like receptor 4 activation through regulation of receptor dimerization and recruitment into lipid rafts in a reactive oxygen speciesdependent manner," Journal of Biological Chemistry, vol. 284, no. 40, pp. 27384-27392, 2009.

[23] S. Huang, J. M. Rutkowsky, R. G. Snodgrass et al., "Saturated fatty acids activate TLR-mediated proinflammatory signaling pathways," Journal of Lipid Research, vol. 53, no. 9, pp. 20022013, 2012.

[24] C.-S. Yang, D.-M. Shin, K.-H. Kim et al., "NADPH oxidase 2 interaction with TLR2 is required for efficient innate immune responses to mycobacteria via cathelicidin expression," Journal of Immunology, vol. 182, no. 6, pp. 3696-3705, 2009.

[25] I. Delint-Ramirez, R. M. Ruiz, I. Torre-Villalvazo et al., "Genetic obesity alters recruitment of TANK-binding kinase 1 and AKT into hypothalamic lipid rafts domains," Neurochemistry International, vol. 80, pp. 23-32, 2015.

[26] M. Milanski, G. Degasperi, A. Coope et al., "Saturated fatty acids produce an inflammatory response predominantly through the activation of TLR4 signaling in hypothalamus: implications for the pathogenesis of obesity," The Journal of Neuroscience, vol. 29, no. 2, pp. 359-370, 2009.

[27] C. D’Mello, T. Le, and M. G. Swain, "Cerebral microglia recruit monocytes into the brain in response to tumor necrosis factora signaling during peripheral organ inflammation," The Journal of Neuroscience, vol. 29, no. 7, pp. 2089-2102, 2009.

[28] R. Maldonado-Ruiz, L. Montalvo-Martínez, L. Fuentes-Mera, and A. Camacho, "Microglia activation due to obesity programs metabolic failure leading to type two diabetes," Nutrition \& Diabetes, vol. 7, no. 3, p. e254, 2017.

[29] S. Nishimura, I. Manabe, M. Nagasaki et al., "CD8 ${ }^{+}$effector T cells contribute to macrophage recruitment and adipose tissue inflammation in obesity," Nature Medicine, vol. 15, no. 8, pp. 914-920, 2009.

[30] M. Feuerer, J. A. Hill, D. Mathis, and C. Benoist, "Foxp3+ regulatory T cells: differentiation, specification, subphenotypes," Nature Immunology, vol. 10, no. 7, pp. 689-695, 2009.

[31] S. Z. Josefowicz, L.-F. Lu, and A. Y. Rudensky, "Regulatory T cells: mechanisms of differentiation and function," Annual Review of Immunology, vol. 30, pp. 531-564, 2012.

[32] G. H. Goossens, E. E. Blaak, R. Theunissen et al., "Expression of NLRP3 inflammasome and T cell population markers in adipose tissue are associated with insulin resistance and impaired glucose metabolism in humans," Molecular Immunology, vol. 50, no. 3, pp. 142-149, 2012.

[33] J. Yu, X. Zhou, M. Chang et al., "Regulation of T-cell activation and migration by the kinase TBK1 during neuroinflammation," Nature Communications, vol. 6, article no. 7074, 2015.

[34] J.-H. Shi and S.-C. Sun, "TCR signaling to NF- $\kappa$ B and mTORC1: Expanding roles of the CARMA1 complex," Molecular Immunology, vol. 68, no. 2, pp. 546-557, 2015. 
[35] V. H. Brait, K. A. Jackman, A. K. Walduck et al., "Mechanisms contributing to cerebral infarct size after stroke: Gender, reperfusion, T lymphocytes, and Nox2-derived superoxide," Journal of Cerebral Blood Flow and Metabolism, vol. 30, no. 7, pp. 13061317, 2010.

[36] J. R. Groom and A. D. Luster, "CXCR3 in T cell function," Experimental Cell Research, vol. 317, no. 5, pp. 620-631, 2011.

[37] M. Kumar, K. Roe, P. V. Nerurkar et al., "Reduced immune cell infiltration and increased pro-inflammatory mediators in the brain of Type 2 diabetic mouse model infected with West Nile virus," Journal of Neuroinflammation, vol. 11, article no. 80, 2014.

[38] S. Rom, V. Zuluaga-Ramirez, N. L. Reichenbach et al., "PARP inhibition in leukocytes diminishes inflammation via effects on integrins/cytoskeleton and protects the blood-brain barrier," $J$. Neuroinflammation, vol. 13, no. 1, p. 254, 2016.

[39] A. M. Dickens, L. B. Tovar-Y-Romo, S. W. Yoo et al., "Astrocyteshed extracellular vesicles regulate the peripheral leukocyte response to inflammatory brain lesions," Science Signaling, vol. 10, no. 473, p. eaai7696, 2017.

[40] C. Mauri and A. Bosma, "Immune regulatory function of B cells," Annual Review of Immunology, vol. 30, pp. 221-241, 2012.

[41] L. Michel, H. Touil, N. B. Pikor, J. L. Gommerman, A. Prat, and A. Bar-Or, "B cells in the multiple sclerosis central nervous system: trafficking and contribution to CNS-compartmentalized inflammation," Frontiers in Immunology, vol. 6, article no. 636, 2015.

[42] K. Lehmann-Horn, S. A. Sagan, C. C. A. Bernard, R. A. Sobel, and S. S. Zamvil, "B-cell very late antigen-4 deficiency reduces leukocyte recruitment and susceptibility to central nervous system autoimmunity," Annals of Neurology, vol. 77, no. 5, pp. 902-908, 2015.

[43] S. R. Shaikh, K. M. Haas, M. A. Beck, and H. Teague, "The effects of diet-induced obesity on B cell function," Clinical and Experimental Immunology, vol. 179, no. 1, pp. 90-99, 2015.

[44] A. Cerutti, M. Cols, and I. Puga, "Marginal zone B cells: virtues of innate-like antibody-producing lymphocytes," Nature Reviews Immunology, vol. 13, no. 2, pp. 118-132, 2013.

[45] C.-X. Yi, M. H. Tschöp, S. C. Woods, and S. M. Hofmann, "High-fat-diet exposure induces IgG accumulation in hypothalamic microglia," DMM Disease Models and Mechanisms, vol. 5, no. 5, pp. 686-690, 2012.

[46] D. B. Ballak, R. Stienstra, A. Hijmans, L. A. B. Joosten, M. G. Netea, and C. J. Tack, "Combined B- and T-cell deficiency does not protect against obesity-induced glucose intolerance and inflammation," Cytokine, vol. 62, no. 1, pp. 96-103, 2013.

[47] S. Rom, V. Zuluaga-Ramirez, H. Dykstra, N. L. Reichenbach, P. Pacher, and Y. Persidsky, "Selective activation of cannabinoid receptor 2 in leukocytes suppresses their engagement of the brain endothelium and protects the blood-brain barrier," The American Journal of Pathology, vol. 183, no. 5, pp. 1548-1558, 2013.

[48] J. R. Lokensgard, M. B. Mutnal, S. Prasad et al., "Glial cell activation, recruitment, and survival of B-lineage cells following MCMV brain infection," Journal Neuroinflammation, vol. 13, no. 1, p. 114, 2016.

[49] L. Carniglia, D. Ramírez, D. Durand et al., "Neuropeptides and microglial activation in inflammation, pain, and neurodegenerative diseases," Mediators of Inflammation, vol. 2017, pp. 1-23, 2017.

[50] G. Colombo, A. Sordi, C. Lonati et al., "Treatment with $\alpha$ melanocyte stimulating hormone preserves calcium regulatory proteins in rat heart allografts," Brain, Behavior, and Immunity, vol. 22, no. 6, pp. 817-823, 2008.

[51] R. Ferreira, T. Santos, M. Viegas et al., "Neuropeptide Y inhibits interleukin- $1 \beta$-induced phagocytosis by microglial cells," Journal of Neuroinflammation, vol. 8, article 169, 2011.

[52] D. Siegl, E. F. Midura, T. Annecke, P. Conzen, C. C. Caldwell, and J. Tschoep, "The effect of ghrelin upon the early immune response in lean and obese mice during sepsis," PLOS ONE, vol. 10, no. 4, Article ID e0122211, 2015.

[53] K. L. J. Ellacott and R. D. Cone, "The role of the central melanocortin system in the regulation of food intake and energy homeostasis: Lessons from mouse models," Philosophical Transactions of the Royal Society B: Biological Sciences, vol. 361, no. 1471, pp. 1265-1274, 2006.

[54] I. Gantz and T. M. Fong, "The melanocortin system," American Journal of Physiology - Endocrinology and Metabolism, vol. 284, no. 3, pp. E468-E474, 2003.

[55] A. Bertolini, R. Tacchi, and A. V. Vergoni, "Brain effects of melanocortins," Pharmacological Research, vol. 59, no. 1, pp. 1347, 2009.

[56] A. B. Cragnolini, C. Caruso, M. Lasaga, and T. N. Scimonelli, “ $\alpha-$ $\mathrm{MSH}$ and $\gamma$-MSH modulate early release of hypothalamic PGE2 and NO induced by IL-1 $\beta$ differently," Neuroscience Letters, vol. 409, no. 3, pp. 168-172, 2006.

[57] M. Lasaga, L. Debeljuk, D. Durand, T. N. Scimonelli, and C. Caruso, "Role of $\alpha$-melanocyte stimulating hormone and melanocortin 4 receptor in brain inflammation," Peptides, vol. 29, no. 10, pp. 1825-1835, 2008.

[58] C. Caruso, M. Sanchez, D. Durand et al., " $\alpha$-Melanocytestimulating hormone modulates lipopolysaccharide plus interferon- $\gamma$-induced tumor necrosis factor- $\alpha$ expression but not tumor necrosis factor- $\alpha$ receptor expression in cultured hypothalamic neurons," Journal of Neuroimmunology, vol. 227, no. 1-2, pp. 52-59, 2010.

[59] T. Ichiyama, T. Sakai, A. Catania, G. S. Barsh, S. Furukawa, and J. M. Lipton, "Inhibition of peripheral NF- $\kappa$ B activation by central action of $\alpha$ - melanocyte-stimulating hormone," Journal of Neuroimmunology, vol. 99, no. 2, pp. 211-217, 1999.

[60] C. Caruso, L. Carniglia, D. Durand, T. N. Scimonelli, and M. Lasaga, "Astrocytes: new targets of melanocortin 4 receptor actions," Journal of Molecular Endocrinology, vol. 51, no. 2, pp. R33-R50, 2013.

[61] K. A. Jablonski, A. D. Gaudet, S. A. Amici, P. G. Popovich, and M. Guerau-de-Arellano, "Control of the inflammatory macrophage transcriptional signature by miR-155," PLoS ONE, vol. 11, no. 7, Article ID e0159724, 2016.

[62] M. Hoch, A. N. Eberle, U. Wagner, C. Bussmann, T. Peters, and R. Peterli, "Expression and localization of melanocortin-1 receptor in human adipose tissues of severely obese patients," Obesity, vol. 15, no. 1, pp. 40-49, 2007.

[63] M. Kojima, H. Hosoda, Y. Date, M. Nakazato, H. Matsuo, and K. Kangawa, "Ghrelin is a growth-hormone-releasing acylated peptide from stomach," Nature, vol. 402, no. 6762, pp. 656-660, 1999.

[64] Y. Qi, K. Inoue, M. Fu, A. Inui, and H. Herzog, "Chronic overproduction of ghrelin in the hypothalamus leads to temporal increase in food intake and body weight," Neuropeptides, vol. 50, pp. 23-28, 2014.

[65] E. T. Vestergaard, N. Jessen, N. Møller, and J. O. L. Jørgensen, "Acyl Ghrelin Induces Insulin Resistance Independently of GH, Cortisol, and Free Fatty Acids," Scientific Reports, vol. 7, p. 42706, 2017. 
[66] C.-Y. Chen, C.-Y. Tsai, W.-J. Lee et al., "Intracerebroventricular O-n-octanoylated ghrelin and its splice variant-induced feeding is blocked by insulin, independent of obestatin or CRF receptor, in satiated rats," Nutrition, vol. 28, no. 7-8, pp. 812-820, 2012.

[67] Y. Iwasaki, K. Dezaki, P. Kumari, M. Kakei, and T. Yada, "Ghrelin counteracts insulin-induced activation of vagal afferent neurons via growth hormone secretagogue receptor," Neuropeptides, vol. 52, pp. 55-60, 2015.

[68] T. D. Müller, R. Nogueiras, M. L. Andermann et al. et al., "Ghrelin," Molecular Metabolism, vol. 4, no. 6, pp. 437-460, 2015.

[69] L. Pacifico, E. Poggiogalle, F. Costantino et al., "Acylated and nonacylated ghrelin levels and their associations with insulin resistance in obese and normal weight children with metabolic syndrome," European Journal of Endocrinology, vol. 161, no. 6, pp. 861-870, 2009.

[70] S. Andarini, F. Bangun, K. Bm, and D. Handayani, "Pre- and postprandial acylated ghrelin in obese and normal weight men," Asia Pacific Journal of Clinical Nutrition, vol. 26, pp. 85-91, 2017.

[71] X. Yin, Y. Li, G. Xu, W. An, and W. Zhang, "Ghrelin fluctuation, what determines its production?" Acta Biochimica et Biophysica Sinica, vol. 41, no. 3, pp. 188-197, 2009.

[72] C. Delporte, "Structure and physiological actions of ghrelin," Scientifica, vol. 2013, pp. 1-25, 2013.

[73] M. François, S. Barde, R. Legrand et al., "High-fat diet increases ghrelin-expressing cells in stomach, contributing to obesity," Nutrition, vol. 32, no. 6, pp. 709-715, 2016.

[74] T. Kouno, N. Akiyama, T. Ito et al., "Ghrelin O-acyltransferase knockout mice show resistance to obesity when fed highsucrose diet," Journal of Endocrinology, vol. 228, no. 2, pp. 115125, 2016.

[75] M. Goebel-Stengel, T. Hofmann, U. Elbelt et al., "The ghrelin activating enzyme ghrelin-O-acyltransferase (GOAT) is present in human plasma and expressed dependent on body mass index," Peptides, vol. 43, pp. 13-19, 2013.

[76] B. Özcan, S. J. C. M. M. Neggers, A. R. Miller et al., "Does desacyl ghrelin improve glycemic control in obese diabetic subjects by decreasing acylated ghrelin levels?" European Journal of Endocrinology, vol. 170, no. 6, pp. 799-807, 2014.

[77] A. Benso, D. H. St-Pierre, F. Prodam et al., "Metabolic effects of overnight continuous infusion of unacylated ghrelin in humans," European Journal of Endocrinology, vol. 166, no. 5, pp. 911-916, 2012.

[78] J. Y. Lee and T. Y. Yune, "Ghrelin inhibits oligodendrocyte cell death by attenuating microglial activation," Endocrinology and Metabolism, vol. 29, no. 3, pp. 371-378, 2014.

[79] D. Stevanovic, V. Starcevic, U. Vilimanovich et al., "Immunomodulatory actions of central ghrelin in diet-induced energy imbalance," Brain, Behavior, and Immunity, vol. 26, no. 1, pp. 150-158, 2012.

[80] M. Moon, H. G. Kim, L. Hwang et al., "Neuroprotective effect of ghrelin in the 1-methyl-4-phenyl-1,2,3,6- tetrahydropyridine mouse model of parkinson's disease by blocking microglial activation," Neurotoxicity Research, vol. 15, no. 4, pp. 332-347, 2009.

[81] J. A. Bayliss, M. Lemus, V. V. Santos, M. Deo, J. D. Elsworth, and Z. B. Andrews, "Acylated but not des-acyl ghrelin is neuroprotective in an MPTP mouse model of Parkinson's disease," Journal of Neurochemistry, vol. 137, no. 3, pp. 460-471, 2016.

[82] M.-M. Theil, S. Miyake, M. Mizuno et al., "Suppression of experimental autoimmune encephalomyelitis by Ghrelin," The Journal of Immunology, vol. 183, no. 4, pp. 2859-2866, 2009.
[83] Y. Xu, Z. Li, Y. Yin et al., "Ghrelin inhibits the differentiation of T Helper 17 cells through mTOR/STAT3 signaling pathway," PLoS ONE, vol. 10, no. 2, Article ID e0117081, 2015.

[84] X. Liu, Q. Xiao, K. Zhao, and Y. Gao, "Ghrelin inhibits high glucose-induced $\mathrm{PC1} 2$ cell apoptosis by regulating TLR4/NF- $\kappa \mathrm{B}$ pathway," Inflammation, vol. 36, no. 6, pp. 1286-1294, 2013.

[85] C. Procaccini, E. Jirillo, and G. Matarese, "Leptin as an immunomodulator," Molecular Aspects of Medicine, vol. 33, no. 1, pp. 35-45, 2012.

[86] A. Pérez-Pérez, T. Vilariño-García, P. Fernández-Riejos, J. Martín-González, J. J. Segura-Egea, and V. Sánchez-Margalet, "Role of leptin as a link between metabolism and the immune system," Cytokine \& Growth Factor Reviews, vol. 35, pp. 71-84, 2017.

[87] C. Procaccini, C. La Rocca, F. Carbone, V. De Rosa, M. Galgani, and G. Matarese, "Leptin as immune mediator: interaction between neuroendocrine and immune system," Developmental \& Comparative Immunology, vol. 66, pp. 120-129, 2017.

[88] E. Papathanassoglou, K. El-Haschimi, X. C. Li, G. Matarese, T. Strom, and C. Mantzoros, "Leptin receptor expression and signaling in lymphocytes: kinetics during lymphocyte activation, role in lymphocyte survival, and response to high fat diet in mice," The Journal of Immunology, vol. 176, no. 12, pp. 77457752,2006

[89] V. Lafrance, W. Inoue, B. Kan, and G. N. Luheshi, "Leptin modulates cell morphology and cytokine release in microglia," Brain, Behavior, and Immunity, vol. 24, no. 3, pp. 358-365, 2010.

[90] L. Larsen, C. Le Foll, A. A. Dunn-Meynell, and B. E. Levin, "IL6 ameliorates defective leptin sensitivity in DIO ventromedial hypothalamic nucleus neurons," American Journal of Physiology - Regulatory Integrative and Comparative Physiology, vol. 311, no. 4, pp. R764-R770, 2016.

[91] Y. Gao, N. Ottaway, S. C. Schriever et al., "Hormones and diet, but not body weight, control hypothalamic microglial activity," GLIA, vol. 62, no. 1, pp. 17-25, 2014.

[92] H. Chung, Y. S. Lee, R. Mayoral et al., "Omega-3 fatty acids reduce obesity-induced tumor progression independent of GPR120 in a mouse model of postmenopausal breast cancer," Oncogene, vol. 34, no. 27, pp. 3504-3513, 2015.

[93] Y. Wang and F. Huang, "N-3 polyunsaturated fatty acids and inflammation in obesity: Local effect and systemic benefit," BioMed Research International, vol. 2015, Article ID 581469, 2015.

[94] D. E. Cintra, E. R. Ropelle, J. C. Moraes et al., "Unsaturated fatty acids revert diet-induced hypothalamic inflammation in obesity," PLoS ONE, vol. 7, no. 1, Article ID e30571, 2012.

[95] H. Liu, Y. Qiu, Y. Mu et al., "A high ratio of dietary n-3/n-6 polyunsaturated fatty acids improves obesity-linked inflammation and insulin resistance through suppressing activation of TLR4 in SD rats," Nutrition Research, vol. 33, no. 10, pp. 849858, 2013.

[96] J. Li, F. R. Li, D. Wei et al., "Endogenous $\omega$-3 polyunsaturated fatty acid production confers resistance to obesity, dyslipidemia, and diabetes in mice," Molecular Endocrinology, vol. 28, no. 8, pp. 1316-1328, 2014.

[97] S. Talukdar, J. M. Olefsky, and O. Osborn, “Targeting GPR120 and other fatty acid-sensing GPCRs ameliorates insulin resistance and inflammatory diseases," Trends in Pharmacological Sciences, vol. 32, no. 9, pp. 543-550, 2011.

[98] N. R. V. Dragano, C. Solon, A. F. Ramalho et al., "Polyunsaturated fatty acid receptors, GPR40 and GPR120, are expressed 
in the hypothalamus and control energy homeostasis and inflammation," Journal of Neuroinflammation, vol. 14, no. 1, 2017.

[99] D.-Y. Guo, D.-W. Li, M.-M. Ning et al., "Yhhu4488, a novel GPR40 agonist, promotes GLP-1 secretion and exerts antidiabetic effect in rodent models," Biochemical and Biophysical Research Communications, vol. 466, no. 4, pp. 740-747, 2015.

[100] D. Y. Oh, E. Walenta, T. E. Akiyama et al., "A Gpr120-selective agonist improves insulin resistance and chronic inflammation in obese mice," Nature Medicine, vol. 20, no. 8, pp. 942-947, 2014.

[101] M. C. Muñoz, J. F. Giani, M. A. Mayer, J. E. Toblli, D. Turyn, and F. P. Dominici, "TANK-binding kinase 1 mediates phosphorylation of insulin receptor at serine residue 994: a potential link between inflammation and insulin resistance," Journal of Endocrinology, vol. 201, no. 2, pp. 185-197, 2009.

[102] S. M. Reilly, S.-H. Chiang, S. J. Decker et al., "An inhibitor of the protein kinases TBK1 and IKK- $\varepsilon$ improves obesity-related metabolic dysfunctions in mice," Nature Medicine, vol. 19, no. 3, pp. 313-321, 2013.

[103] E. A. Oral, S. M. Reilly, A. V. Gomez et al., "Inhibition of IKK $\varepsilon$ and TBK1 improves glucose control in a subset of patients with type 2 diabetes," Cell Metabolism, vol. 26, no. 1, pp. 157-170.e7, 2017.

[104] P. J. D. Delhanty, M. Huisman, L. Y. Baldeon-Rojas et al., "Desacyl ghrelin analogs prevent high-fat-diet-induced dysregulation of glucose homeostasis," FASEB Journal, vol. 27, no. 4, pp. 1690-1700, 2013.

[105] M. K. Wellman, Z. R. Patterson, H. MacKay et al., "Novel regulator of acylated ghrelin, CF801, reduces weight gain, rebound feeding after a fast, and adiposity in mice," Frontiers in Endocrinology, vol. 6, 2015.

[106] K. R. McGovern-Gooch, N. S. Mahajani, A. Garagozzo et al., "Synthetic triterpenoid inhibition of human ghrelin o-acyltransferase: the involvement of a functionally required cysteine provides mechanistic insight into ghrelin acylation," Biochemistry, vol. 56, no. 7, pp. 919-931, 2017. 

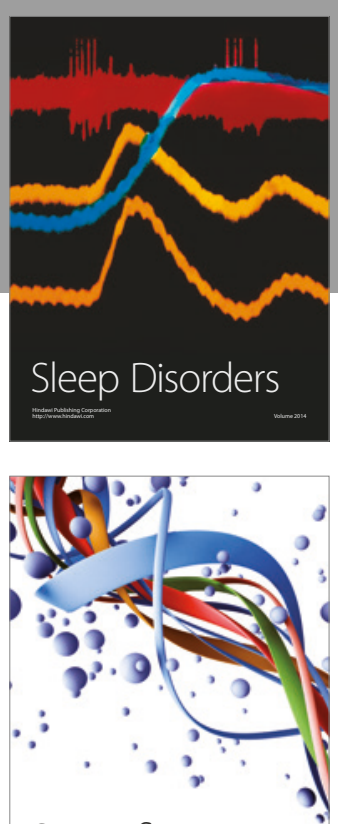

Scientifica
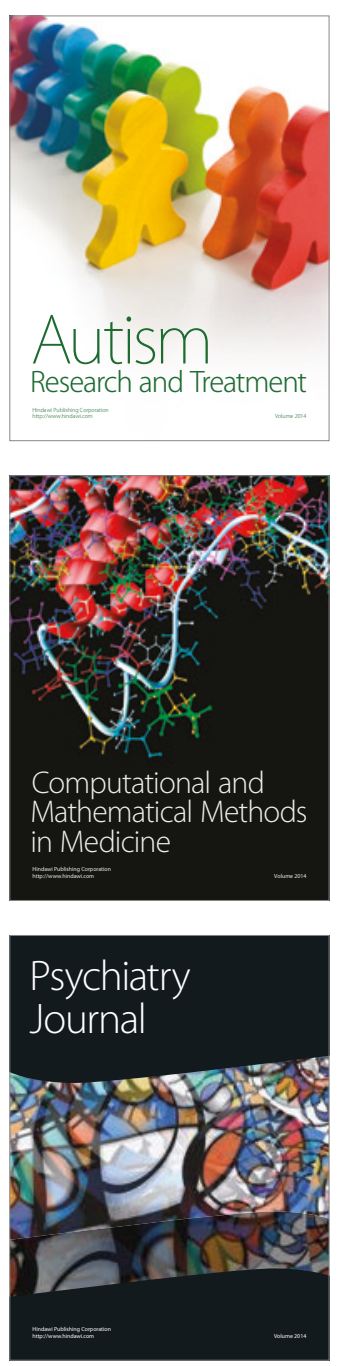
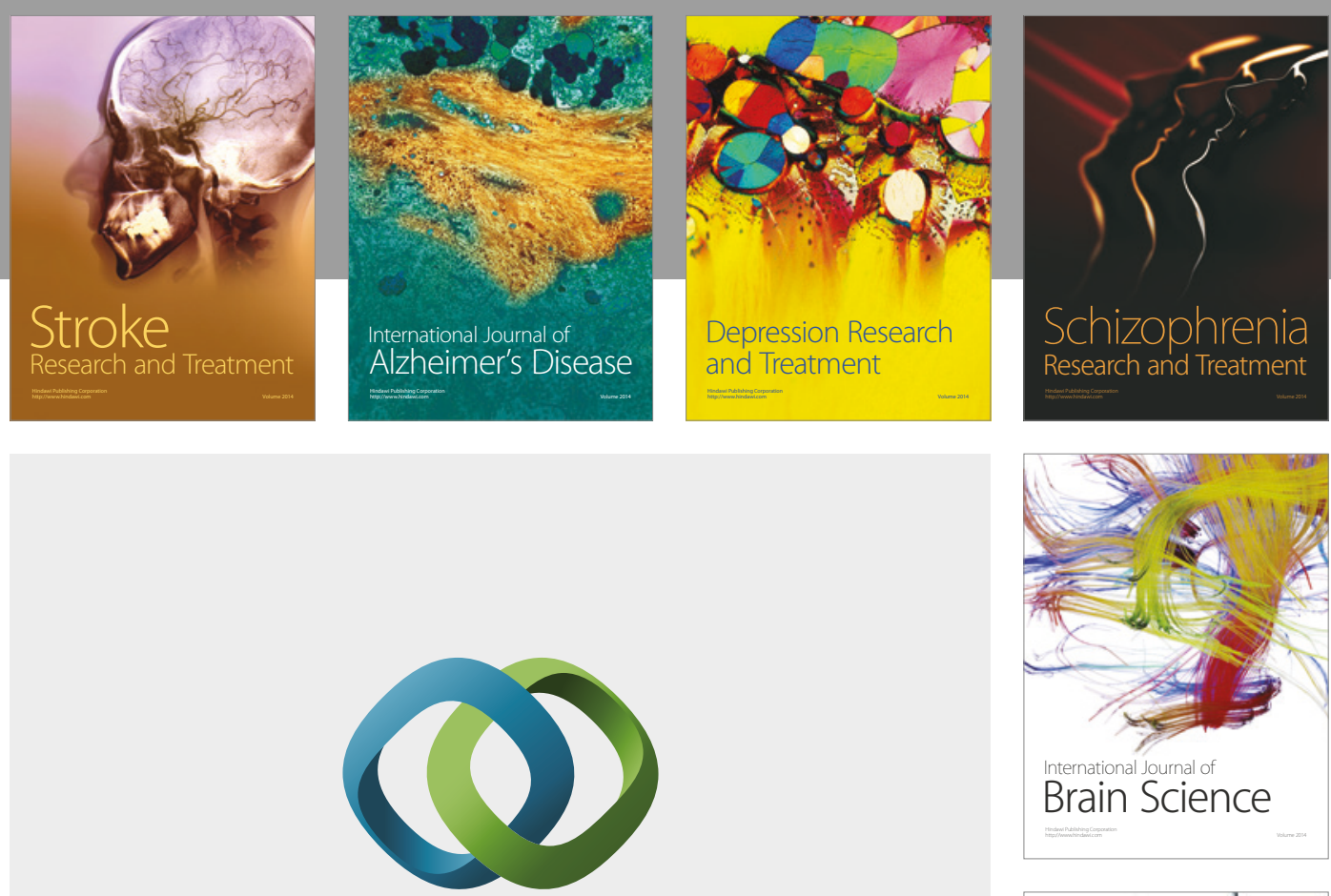

\section{Hindawi}

Submit your manuscripts at

https://www.hindawi.com
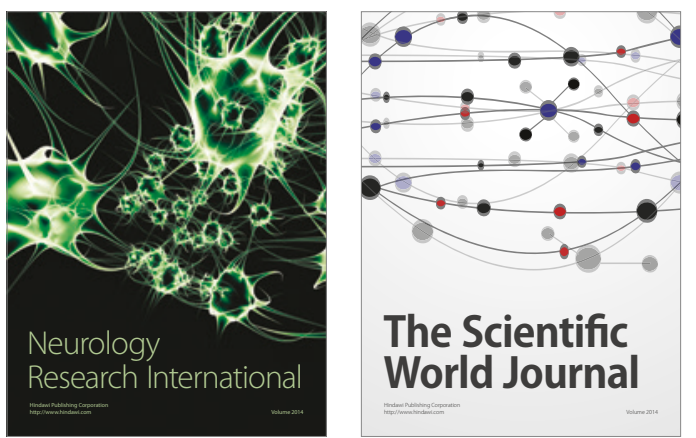

The Scientific World Journal

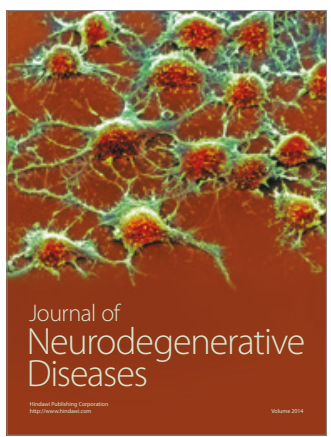

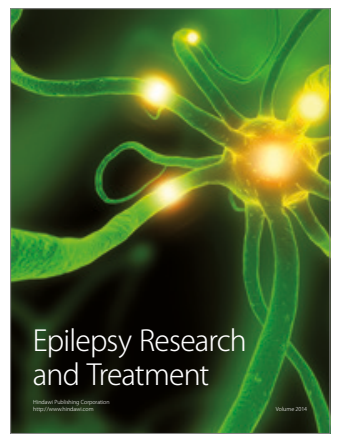

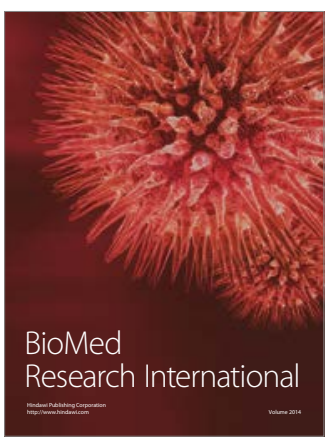

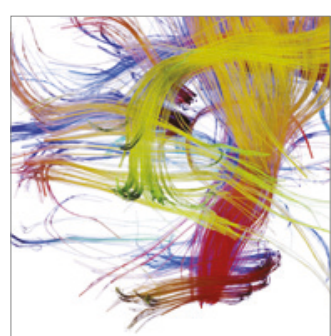

Brain Science

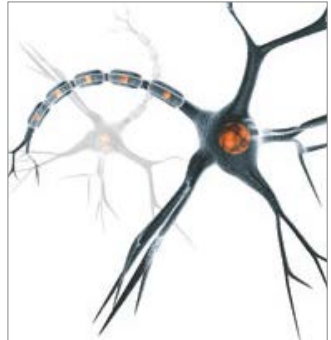

Neural Plasticity
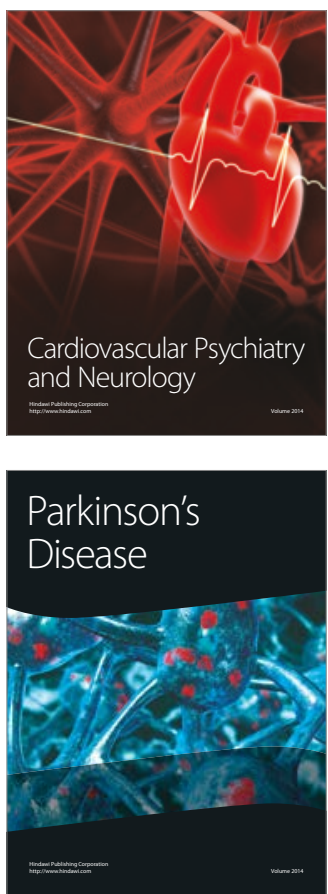